\title{
PARA SE PENSAR E CRIAR OUTROS TIPOS DE NARRATIVAS: TERRITÓRIOS MIDIÁTICOS E MÍDIA TÁTICA PARA CRIANÇAS NO CONTEXTO DA FAVELA DA PROVIDÊNCIA
}

TO THINK AND CREATE OTHER TYPES OF NARRATIVES: MEDIA TERRITORIES AND TACTICAL MEDIA FOR CHILDREN IN THE CONTEXT OF DE MORRO DA PROVIDÊNCIA

\section{Luiza Cunha Barata1}

ENVIADO EM: 02/03/2020 | ACEITO EM: 03/06/2020

DOI: $10.5902 / 2317175842704$

\section{RESUMO}

A falta de representatividade midiática e a proliferação de ferramentas tecnológicas nos grandes centros urbanos vêm motivando a construção de novos territórios midiáticos. Durante pesquisa etnográfica realizada no Morro da Providência para entender a relação daqueles moradores com a mídia corporativa, foi possível identificar que tal insatisfação e o encorajamento para se percorrer outros tipos de narrativas vêm sendo passado, inclusive, às crianças. A proposta deste artigo é analisar impactos dessas iniciativas comunicacionais ainda na infância.

Palavras-chave: Territórios midiáticos; Mídia tática; Comunicação Social; Conflito urbano. 
PARA SE PENSAR E CRIAR OUTROS TIPOS DE NARRATIVAS: TERRITÓRIOS MIDIÁTICOS E MÍDIA TÁTICA PARA CRIANÇAS NO CONTEXTO DA FAVELA DA PROVIDÊNCIA

\section{ABSTRACT}

The lack of media representation and the proliferation of technological tools in large urban centers have been motivating the construction of new media territories. During the ethnographic research carried out at Morro da Providência to understand the relationship between residents and corporate media, it was possible to identify satisfaction and encouragement to go through other types of narratives previously shown, including for children. The purpose of this article is to analyze impacts of these communication initiatives in childhood.

Keywords: Media territories; Tactical media; Communication; Urban conflict.

\section{Introdução}

Era em um casarão próximo à quadra esportiva do Morro da Providência, na Zona Portuária do Rio de Janeiro, onde a Sessão Curumim acontecia praticamente uma vez por mês, em 2017. Desde então, a iniciativa de cinema voltada para crianças já passou por outros pontos da favela, como o viaduto do Santo Cristo e a Praça dos Cajueiros. As exibições fazem parte do projeto Favela Cineclube, que busca reunir moradores e grupos de fora da Providência para assistir a filmes e debater sobre os temas.

Pelas redes sociais, as organizadoras contam que o Favela Cineclube "vem desde agosto de 2016 exibindo filmes que carregam valores do gueto e a ressignificação do povo preto e pobre das Favelas e periferias do mundo todo" (NOTA DE CAMPO, 10/11/19). Em extensão a este ideal e com adaptações para o público infantil estão as sessões Curumim.

As atividades para os pequenos são bem similares ao projeto destinado aos adultos, como, por exemplo, filmes e desenhos que são exibidos e que nem sempre têm destaque na grande mídia. Além disso, propagam a ideia de que a favela também é lugar para se consumir cinema, o que raramente é dito em espaços midiáticos. Se há algo que se acentua durante a Sessão Curumim é o incentivo, por parte das organizadoras, para que os participantes também passem a construir e divulgar suas próprias histórias - tudo desde cedo.

Recentemente, a região da Providência passou por várias mudanças estruturais e esteve sob atenção dos principais veículos de comunicação do país. Nos últimos dez anos, a cidade do Rio de Janeiro esteve imersa em um profundo processo de obras e adequações para receber uma sequência de megaeventos. Em especial, as Olimpíadas de 2016. Dentro deste contexto, o projeto de revitalização da Zona Portuária tomou forma e foi considerado pelo então prefeito Eduardo Paes como o principal legado olímpico para os cariocas.

As obras tiveram início com a emblemática demolição do elevado da Perimetral. Houve ainda a construção de museus, prédios de escritório e moradia, bem como a formação de um novo pólo gastronômico, a abertura de ave- 
nidas, a realização de uma das mais emblemáticas ações de segurança pública, a instalação das Unidades de Polícia Pacificadora, e o início do emblemático programa habitacional Morar Carioca no Morro da Providência.

Freitas, Lins e Carmo (2016) apontam que a forma com que megaeventos se relacionam com as cidades-sede e suas consequências são imprevisíveis. No entanto, destacam que é uma tendência da mídia corporativa se concentrar em tratar tal cenário de maneira bastante otimista. Os relatos que tendem a circular falam das grandes obras quase sempre como interferências necessárias, transformadoras e positivas tanto para a realização do grande evento, quanto para quem vive nestes espaços, o que, como se sabe, não se concretiza dessa forma para todos. No caso da Providência, por exemplo, as obras previam a remoção de centenas de famílias e aconteceram de forma abrupta. Versões de narrativas sobre a reforma urbana que não circularam pela mídia convencional, mas que circularam por outros espaços midiáticos.

A falta de identificação de pessoas "comuns" com o que é publicado por grandes jornais e o maior acesso às ferramentas digitais têm impulsionado novas formas de produções midiáticas e propagado outras vozes sobre diversos eventos. Para explicar o fenômeno, Simone Tosoni e Matteo Tarantino (2013) trazem o conceito de "territórios midiáticos" (media territories). São táticas simbólicas utilizadas por atores envolvidos em um conflito urbano em cidades midiatizadas para promover representações específicas de si. É um termo usado para dar conta de conjuntos heterogêneos de plataformas de mídia, conteúdos e dispositivos mobilizados por atores sociais para dar sentido ao conflito e impor, de certa forma, representações a respeito deles mesmos, de outras figuras que constituem a disputa e do espaço urbano.

O objetivo deste artigo é tentar entender como esses territórios midiáticos podem se voltar para crianças imersas no conflito urbano. Em tais espaços, onde há constante disputa pelo espaço da cidade, ferramentas tecnológicas disponíveis e um sentimento generalizado de falta de representatividade midiática, existe também o estímulo de iniciativas "nós por nós" que fazem o convite para o público infanto-juvenil não se contentar somente com o que é dito pelos jornais. Para atender a este recorte, serão analisadas impressões da Sessão Curumim.

O artigo será dividido em três etapas. A primeira delas buscará contextualizar a transformação urbana realizada na favela da Providência e suas motivações. Além disso, serão trazidas questões referentes à realização de megaeventos, a tendência da grande mídia em abordar o tom otimista, na maior parte do tempo, e o uso da internet como impulsionador para que pessoas expressem suas perspectivas.

A segunda parte da publicação vai trazer uma análise sobre a Sessão Curumim, realizada na Providência em dezembro de 2017. Será utilizada a inspiração etnográfica, (BARROS, 2008) como abordagem e filosofia metodológicas. De maneira bastante resumida, a etnografia pode ser considerada um 
tipo de abordagem metodológica que se refere à prática de fazer trabalho de campo etnográfico e às suas representações. E a inspiração etnográfica é considerada uma adaptação do método, com reduções do tempo de permanência e envolvimento com o grupo em questão. Por fim, pretendo relacionar os princípios de midiativismo que o projeto tem com os conceitos de territórios midiáticos e mídia tática.

\section{Breve contexto da favela da Providência e questões midiáticas}

Historicamente, se falamos em mais de cem anos de existência de favelas na cidade do Rio de Janeiro, também podemos dizer que são quase mais de cem anos de políticas que, pelo menos em algum momento, se confundiram com ações de extermínio destes espaços. Assim como se repetiu durante a formação de outras favelas que viriam a se desenvolver, moradores do Morro da Providência alternaram períodos de ausência do poder público em diferentes áreas, como saúde e segurança, com outros de presença ostensiva de agentes da ordem pública.

O programa habitacional Morar Carioca foi criado em momento decisivo, aliado à instalação das Unidades de Polícia Pacificadora ${ }^{3}$, um dos principais projetos da Secretaria Estadual para as favelas do Rio, incluindo a Providência. A principal justificativa era de que seria preciso "ajeitá-las" para adequar a cidade às necessidades do megaevento. Até hoje, foi o maior projeto já anunciado, em todo o país, voltado para a infraestrutura de comunidades faveladas.

Para a antropóloga Mariana Cavalcanti (2017), o lançamento do Morar Carioca foi considerado como "uma época muito esperançosa e otimista", na qual uma série de políticas de infraestrutura, moradia, e temas sociais estavam emergindo para transformar radicalmente o Rio de Janeiro. Com o avanço das obras, o projeto, inseriu de forma obrigatória não só reflexos da transformação do Rio de Janeiro em cidade olímpica na Providência. Mas, de maneira mais ampla, contribuía também para propagar o que estudiosos de megaeventos chamam de "a ideia do mundo perfeito" que megaeventos precisam proporcionar às cidades.

Beatriz Jaguaribe (2011) aponta que não era por acaso que o plano de intervenção urbana se intensificaria nestes espaços (das favelas) durante a preparação para o megaevento da Olimpíada. Para a pesquisadora, as favelas cariocas acabaram virando trademark da cidade do Rio de Janeiro. Há a mistura entre o fascínio e o horror frente à imagem de favelas violentas, degradadas e o fascínio e glamour da favela estilizada e autêntica.

A partir do momento em que uma cidade se torna palco do grande evento, é preciso promover alterações na vida e cotidiano, nos mínimos detalhes possíveis, principalmente por meio de programas de cunho social, para tentar suprir o momento fantasioso, que nunca chega a se concretizar, em que 3 As UPPs foram adotadas como principal estratégia da Secretaria Estadual de Segurança para retomada de território de favelas controladas pelo tráfico, por meio da permanência policial nestes territórios. 
a maioria das pessoas conseguiria aproveitar possibilidades multissensoriais do espetáculo.

A materialização da utopia de um "mundo perfeito", que surge e se esvai como por encanto, desperta os olhares das pessoas, não só para aquele espaço mágico, mas, para a dureza da realidade que o emoldura, que se espera ser bela, experiencial e afetiva, tal qual pretendem os megaeventos (FREITAS; LINS; CARMO, 2016, p. 22).

É como se fosse uma tentativa, principalmente, por parte das gestões regionais, de transformar os megaeventos em motores de transformação social e minimizar o contraste que passa a existir entre a grandiosidade que o megaevento exige com áreas menos beneficiadas das cidades-sede.

Porém, isso nem sempre é bem executado e, frequentemente, promove revolta para comunidades locais. Para que o "espírito olímpico" chegasse à Providência, era preciso que 671 famílias fossem removidas da localidade e realocadas em prédios de conjuntos habitacionais do programa Minha Casa, Minha Vida, muitas vezes em bairros distantes em até trinta quilômetros daquela região. A principal justificativa para isso era de que as casas estavam em situação "de risco", sem maiores explicações para o que tornava determinada habitação "de risco" e outras ao redor, não.

Em uma das poucas entrevistas de moradores publicadas na grande mídia sobre remoções motivadas pelas Olimpíadas, Dona Chiquinha, moradora há 40 anos da Providência, revelava que o que acontecia ali passou a ser chamado de "terror psicológico": "(...) ninguém explica o que vai acontecer conosco e o que significa essa pichação nas nossas portas. Daqui eu não saio" (O DIA, 2013). As pichações, às quais Dona Chiquinha se refere, eram as iniciais da Secretaria Municipal de Habitação (SMH), que se espalharam da noite para o dia nas portas das casas.

Historicamente, grupos minoritários agem pelo que Henry Lefebvre (2015) chama de "direito à cidade", que seriam formas de buscar representatividade e, principalmente, garantir, por meio dela, o cumprimento de direitos que garantam a permanência desses grupos em centros urbanos. A prática não é nova. De acordo com o pesquisador Leonardo Custódio (2016), desde o início da década de 1940, grupos passaram a se organizar em grupos de ações coletivas para lutar por temas ligados à disputa do território urbano (p. 16).

O conceito "midiativismo de favela" é uma tentativa de dar conta da complexidade dos usos políticos de mídia e jornalismo entre moradores de favelas. O midiativismo de favela não está restrito à própria favela. Apesar de ser claramente produzido com o objetivo de que seja da favela para a própria e também para outras favelas, a intenção é justamente fazer com que discussões que cabem a esses territórios alcancem o restante da cidade. Novas formas de midiativismo de favela foram e têm sido constantemente impulsionadas e 
renovadas por meio das novas tecnologias da informação e da comunicação, principalmente por meio do ciberespaço. Isso porque o ciberespaço, diferente de outros tipos de mídia, pode permitir maior participação dos grupos marginalizados na produção daquilo que circula.

(...) os movimentos sociais dependem da existência de mecanismos de comunicação específicos: boatos, sermões, panfletos e manifestos passados de pessoa a pessoa, a partir do púlpito, da imprensa ou por qualquer meio de comunicação disponível. Em nossa época, as redes digitais, multimodais, de comunicação horizontal, são os veículos mais rápidos e mais autônomos, interativos e reprogramáveis e amplificadores de toda a história (CASTELLS, 2012, p. 19-20).

Para Hall (2003), nos processos midiáticos, a produção faz parte de um jogo de negociação de uma complexa estrutura dinâmica sobre questões da distribuição, do consumo, da circulação e reprodução. Enquanto nas principais plataformas de mídia moradores de favelas geralmente não conseguem destaque - ou muitas vezes são reduzidos a notícias sobre criminalidade e tráfico no ciberespaço, essas pessoas podem, muitas vezes, ser sujeitos nos processos instaurados, e fazer circular temáticas relevantes para a própria favela. A internet é vista como dispositivo para que moradores de favela busquem maior autonomia nos processos midiáticos.

As chances de deslocamento no tempo e no espaço fazem do mundo online ponto estratégico capazes de conectar cidades e favelas. Não que as diferenças entre cidade formal e regiões marginalizadas sejam apagadas, mas podem ser significantemente atenuadas por conta da estrutura global da internet. A partir do momento que contamos com o acesso à Internet, torna-se muito fácil encontrar inúmeras publicações ao buscarmos por algumas palavras-chave como "moradores", "Providência" e "remoções", por exemplo.

Se as Olimpíadas aceleraram as interferências que o poder público fazia nas favelas, ela também foi capaz de encorajar a publicação de relatos dos próprios moradores sobre aquelas transformações, principalmente durante os jogos. Não que isso seja capaz de amenizar o impacto das casas demolidas, mas o ápice da situação de conflito, como Castells (2013) mostra, também incentiva e acelera a circulação e produção independentes de conteúdo. Afinal, se os olhos de todo o mundo estavam voltados para o Rio de Janeiro, o momento se mostrava oportuno também para reivindicar direitos e denunciar ações abusivas, mesmo que fosse por conta própria.

\section{Experiência etnográfica na Sessão Curumim}

Para entender alguns dos impactos e particularidades da narrativa "nós por nós" para crianças, participei da Sessão Curumim em dezembro de 2017. Inicialmente, minhas idas à favela da Providência tinham como objetivo prin- 
cipal analisar a relação dos moradores (adultos) com a mídia. A análise feita durante a sessão de cinema infantil foi, portanto, um desdobramento da atividade no campo. Como as idas às sessões Curumim foram esporádicas, a metodologia utilizada neste artigo será a inspiração etnográfica. Método que conserva em si princípios da abordagem antropológica, mas que com certas adaptações.

De maneira geral, considera-se que a etnografia combina o engajamento de pessoas com determinados fenômenos e é uma forma de mapear e ajudar a compreender determinada cultura ou ambiente social. Não existe caminho pré-estabelecido a ser percorrido durante a pesquisa etnográfica, mas há uma combinação de métodos, como entrevistas, análise visual e observações, que podem ser participativas, que podem levar a diferentes tipos de resultados e percepções sobre grupos sociais.

Para Robert Kozinets (2014), a etnografia, por si só, varia de acordo com as necessidades que cada contexto de pesquisa pode exigir:

\begin{abstract}
A pesquisa etnográfica permite que o pesquisador adquira uma compreensão detalhada e sutil de um fenômeno social, e depois capte e comunique suas qualidades culturais. Ela fornece um senso da experiência vivida pelos membros da cultura, assim como uma análise fundamentada da estrutura do seu grupo, como ele funciona e como ele se compara a outros grupos. (KOZINETS, 2014, p. 58).
\end{abstract}

Para entender o ponto de vista "do outro", é necessário partilhar de sua realidade, sua descrição do mundo e seu conjunto de significados. Ao realizar investigações antropológicas um pouco mais imediatas voltadas para ações de consumo e marketing, Carla Barros (2008) aponta que a inspiração etnográfica pode permitir adaptações como a redução do tempo de permanência em campo, o contato intermitente com o grupo estudado e a intensidade com o grupo.

Adaptações essas que precisei fazer durante o breve contato que tive com os participantes da sessão de cinema, tentando constantemente manter "o fio condutor dos estudos etnográficos em geral" (BARROS, 2008).

Conheci Fatima Lima, uma das responsáveis pelo Favela Cineclube, em 2017, quando fiz trabalho de campo para a dissertação do mestrado 4 . Com a ajuda de uma colega da Universidade Federal Fluminense que já realizava trabalhos de publicidade com o Favela Cineclube, troquei mensagens com a moradora da Providência pelo WhatsApp.

Havia alguns meses, Fatima tinha recebido colaborações para a divulgação do cineclube através de um projeto da universidade, o que certamente contribuiu para que ela fosse (mais) receptiva à minha abordagem.

Fatima chegou a ser removida durante as obras do Morar Carioca e foi realocada para um dos poucos conjuntos habitacionais disponíveis no Centro

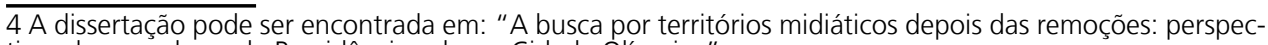
tivas de moradores da Providência sobre a Cidade Olímpica". 
do Rio de Janeiro. Ela é uma das inúmeras moradoras da Providência que usa as redes sociais com fins ativistas.

Nosso primeiro encontro aconteceu em novembro, durante uma das atividades do Favela Cineclube e, finalmente, em dezembro participei da Sessão Curumim. A divulgação das sessões é feita no Facebook da página do Favela Cineclube e também por panfletos entregues aos responsáveis pelas crianças. Pela primeira vez, as crianças não só assistiriam ao filme, mas também participariam de uma oficina de curtas-metragens.

A ideia era que elas fossem as protagonistas das histórias que quisessem registrar. Em nenhum momento tive contato com familiares dos participantes e, como todos eram menores de idade, não foi possível a realização de entrevistas com eles. Pela mesma razão, as crianças não serão identificadas pelos nomes neste trabalho.

$\mathrm{Na}$ data, Fatima me encontrou próximo a um dos acessos à Providência e, quando chegamos ao casarão onde a sessão aconteceria, me deparei com um grupo de dezesseis crianças, todas com até doze anos. A tecnologia certamente é uma das aliadas das atividades do clube de cinema em muitos aspectos: do processo de divulgação das sessões até a execução de cada um dos encontros. Quando chegamos ao ponto de encontro, Fatima depositou o celular em cima da mesa e logo foi para o computador, acertar questões técnicas de como aconteceria a transmissão dos vídeos.

Nenhuma das crianças leva smartphones para a Sessão Curumim. Os aparelhos não são novidades para o grupo, mas pelo que pôde ser observado elas costumam usar os celulares de familiares adultos ou adolescentes quando estão em casa. Sendo assim, Fatima, eu e mais duas das organizadoras, Marcia e Barbara, cedemos nossos aparelhos e acompanhamos as crianças durante as gravações. Barbara foi quem proporcionou a eles breves explicações sobre técnicas básicas de cinema e logo fomos para uma praça que fica na Ladeira do Faria.

Coube a mim acompanhar um grupo com quatro meninas ${ }^{5}$. Da mesma forma que eu queria saber a história de cada uma delas, elas também buscaram saber de onde eu vinha. Antes de iniciarmos as filmagens, P. quis saber se eu morava na Providência, imagino que ela presumia que sim, porque antes mesmo de conseguir responder, a menina me questionou porque eu nunca havia aparecido no cineclube antes.

Contei que morava em um bairro na Zona Norte, e expliquei que tinha ido àquela sessão para fazer uma pesquisa para a faculdade, fato com o qual ela prontamente se encantou. Em resposta, P. disse que "também estava na escola" e, satisfeita, me contou que estava muito empolgada com estudos, afinal, "já estava indo para o quinto ano" (NOTA DE CAMPO, 13/12/17).

S. e L. queriam observar nossa interação e pareciam bastante desconfiadas, mas ao longo das cenas que inventamos, acabaram se soltando e entraram na brincadeira. Ao todo, gravamos três cenas de um minuto cada: uma em

5 As meninas serão identificadas como P., S., L. e D. 
que as meninas foram se revezando em brinquedos da pracinha, outra em que quiseram imitar a estátua do Cristo Redentor - que é visível da praça onde estávamos - e uma terceira muito fiel ao cotidiano feminino e ligada às questões da casa: o ato de cuidar de crianças.

Neste aspecto há algo interessante a ser observado. É bem verdade que a proposta da atividade era justamente fazer o registro de quaisquer cenas ligadas àquele cotidiano, mas a rapidez com que as crianças elaboraram as histórias para serem gravadas pelo celular mostrou a familiarização tanto com a ferramenta, quanto com o cenário onde vivem. O celular foi incorporado naquele contexto como mais uma ferramenta disponível. Não existiam grandes expectativas para lidar com o aparelho, em si, mas para executar o que haviam aprendido. Rapidamente, elaboraram diálogos, me indicaram ângulos para filmá-las e agiram com bastante naturalidade. $\mathrm{O}$ uso do telefone como ferramenta que registra cenas do dia a dia é completamente banal.

Quando terminávamos as gravações, logo elas vinham correndo até mim para revisar o material, tecendo comentários como "não estou bonita nesta imagem" ou "queria fazer de novo porque não falei bem" (NOTA DE CAMPO, 13/12/17). E isto demonstra certa aproximação da lógica do que circula pela grande mídia que, geralmente, preza pela alta qualidade da imagem, pela aparência e entonação das pessoas, por exemplo, como fatores determinantes para validar se determinado material pode ou não ser exibido.

De volta ao casarão do Favela Cineclube, assistimos aos vídeos que foram feitos e as meninas se disseram satisfeitas com o resultado final. Apesar de mais desenvolta durante a produção, P. foi a que se mostrou mais ansiosa durante o tempo em que aguardávamos pela exibição de nosso vídeo. D. logo entregou a amiga "é que $P$. se preocupa muito com o que falam dela" (NOTA DE CAMPO, 13/12/17).

Durante a exibição dos curtas, a expectativa das crianças para verem o que as outras tinham gravado era enorme. Mesmo que todas conhecessem o funcionamento de um smartphone, a transposição das imagens gravadas do celular para o projetor e as de todos reunidos para ver o que havia sido gravado aumentou o potencial cinematográfico da atividade. Neste momento, o vídeo gravado pelo celular ganhou caráter de curta-metragem que seria exibido para todos, como se estivéssemos em um cinema. E este cenário foi o mais próximo que grande parte dos participantes chegou das telas: a maioria nunca havia estado em uma sala de cinema.

Os outros grupos - dois deles com meninos e meninas e um exclusivamente formado por meninos - preferiram gravar cenas voltadas para temáticas mais variadas, como, por exemplo, um alerta ao combate do trabalho infantil e uma partida de futebol.

Depois de assistirmos aos vídeos, P. comentou que ainda não tinha um celular "só para ela", mas não via a hora de ter um Iphone, "mas daqueles bem modernos, mesmo", fazendo referência ao meu celular já bastante ultra- 
passado. Como a família toda já era conectada, o padrasto da menina estava providenciando o aparelho: ela imaginava que seria seu presente de Natal. Quando perguntei para quê ela usaria o aparelho, P. não pensou duas vezes: "preciso falar com a minha mãe o dia todo, vamos trocar WhatsApp sempre" (NOTA DE CAMPO, 13/12/17).

Quando fui embora do cineclube, Marcia, uma das organizadoras, me acompanhou de volta até a Central do Brasil e pôde me confirmar toda a preocupação que as mulheres têm com as crianças. As sessões não são apenas para diversificar o repertório midiático de quem cresce na Providência. Em muitos momentos, servem para preencher lacunas no relacionamento das crianças com a própria família nuclear como, por exemplo, cobrar a frequência na escola.

\section{Questões dos territórios midiáticos e de mídia tática}

Na publicação "A Internet e a rua", os pesquisadores Fábio Malini e Henrique Antoun (2013) mostram que desde 2013 os embates entre a mídia tradicional e as iniciativas alternativas que passaram a ter a internet como ferramenta na disputa pela construção de narrativas foram impulsionadas.

A Mídia Ninja fez emergir e deu visibilidade ao "pós-telespectador" de uma "pósTV" nas redes, com manifestantes virtuais que participam ativamente dos protestos/ emissões discutindo, criticando, estimulando, observando e intervindo ativamente nas transmissões em tempo real e se tornando uma referência por potencializar a emergência de "ninjas" e midialivristas em todo o Brasil. Indo além do "hackeamento" das narrativas, a Mídia Ninja passou a pautar a mídia corporativa e os telejornais ao filmar e obter as imagens do enfrentamento dos manifestantes com a polícia, a brutalidade e 0 regime de exceção [...]. (MALINI; ANTOUN, 2013, p.15).

A partir de tal momento, multiplicam-se os conceitos que tentam dar conta aos novos formatos de mídia impulsionados pela disseminação das ferramentas de tecnologia. Um modelo apresentado pelos dois especialistas seria o midialivrismo ciberativista: um conjunto de experiências de desenvolvimento de dispositivos, processos de comunicação e tecnologias, a partir da ideia da colaboração social em rede e de tecnologias, que têm como objetivo a produção livrem sem quaisquer níveis de hierarquia.

O midiativismo de favela, de Leonardo Custódio (2013), trata especificamente sobre as estratégias que fazem ecoar de maneira engajada lutas do dia a dia nos centros urbanos, por justiça, dignidade, direitos, valorização de tradições e culturas e outros tantos assuntos políticos que fazem parte da vida nas favelas. Neste processo, vozes e debates de grupos marginalizados ganham força e conseguem, inclusive, influenciar narrativas jornalísticas.

A Sessão Curumim promove rodas de conversa em que as organizadoras explicam a importância das crianças elaborarem histórias e estimularem 
a imaginação sempre que puderem. Os conselhos não tratavam da atividade com celular, em si. Na realidade, falavam sobre o potencial que aquele público poderia ter para construir narrativas midiáticas.

É importante ponderar que, em nenhum momento, há alguma mensagem dando a entender que seria mais adequado elas não lerem determinado livro ou não assistirem a desenhos, por exemplo, que passam na TV. Assim como a grande maioria das pessoas desta faixa etária, aquele grupo conhecia novelas que estavam em alta, nomes de emissoras e diversos desenhos animados exibidos nos principais canais.

O objetivo do projeto não é definir quais trajetórias de mídia as crianças vão tomar. A principal finalidade é mostrar que há uma infinidade de histórias a serem ouvidas e contadas, inclusive por elas, que podem valorizar a realidade em que vivem e que podem gerar maior representatividade em relação ao grupo.

Em um exemplo prático, Marcia me contou que em determinado dia encontrou algumas das meninas dançando pelas vielas da Providência, ao som de uma música que falava sobre sexo. "Eu não vou falar para elas 'não ouçam isso'. O que eu fiz foi apresentar a elas outros cantores. Algum tempo depois, vi o grupo ouvindo Rincon Sapiência. Ele canta sobre favela, gente negra...é importante que elas saibam que tem gente cantando sobre o que elas vivem. Gera uma identificação, sabe?" (NOTA DE CAMPO, 13/12/17).

Talvez o território midiático das sessões Curumim ainda não seja exatamente concreto para crianças, mas é parte do processo de construção de representatividade que elas se encontram. Se, por definição, territórios midiáticos são operações discursivas realizadas por atores sociais que têm como principal objetivo ganhar posições vantajosas dentro de um conflito urbano, é possível dizer que o projeto Curumim funciona como preparação para crianças lidarem com tais dilemas de mídia, futuramente.

As crianças têm plena consciência de que vivem na favela, conhecem o lugar onde moram e as relações que estabelecem. No geral, têm os cenários da vizinhança e do colégio como principais referências para se localizarem no espaço/tempo, mas ainda não têm dimensão total em relação sobre o que é a grande mídia e questões sobre ela: como, por exemplo, se o que é exibido por telejornais representa ou não o que elas vivem e se aquilo é capaz de contemplá-las, enquanto moradoras de uma favela.

Há o constante incentivo para que as crianças percorram e criem novos territórios midiáticos, vindo de adultos que não se identificam com aquilo que circula pela grande mídia. Algo que funciona como uma espécie de reparação geracional, na expectativa de que aquelas crianças não precisem atravessar a futura frustração de dependerem de veículos de imprensa que, em muitos momentos, deixaram de lado seus antepassados.

Em uma análise um pouco mais ampla, sobre a Sessão Curumim, em si, é possível traçar um paralelo com o conceito de mídias táticas. Anna Feigenbaum, Patrick McCurdy e Fabian Frenzel (2013) estabelecem que mídias 
táticas são exemplos de mídia que se baseiam na questão de experimentação e do "faça você mesmo" como ações capazes de contestar o poder da mídia corporativa e produzir novos formatos de mídia.

A mídia tática não foi inaugurada pelo uso das novas ferramentas de tecnologia, mas, sem dúvidas, tem sido impulsionada por elas nos últimos anos, e também pela presença estruturas (físicas) ou eventos realizados em grandes centros urbanos que são capazes de emitir mensagens e, por isso, tornam-nos midiáticos.

Os autores pontuam que três características essenciais facilitam o entendimento sobre a mídia tática: a contestação do poder da mídia corporativa, a produção de mídia ativista e a desobediência enquanto projeto territorial.

Pelo que pude observar, o Favela Cineclube, como um todo - não só as sessões Curumim - estimula e incentiva que participantes questionem a produção midiática tradicional que grandes jornais fazem a respeito de favelas. Em primeiro lugar, porque acontecem dentro do morro da Providência, em espaços onde equipes de reportagem raramente fazem a cobertura jornalística. Até mesmo quando há casos de violência, um dos temas mais frequentes de ser associado à favela, a cobertura jornalística acaba restrita aos arredores das favelas e não mostra, portanto, que espaços são esses da região favelada em questão.

Promove ainda críticas a respeito da mídia corporativa, mesmo quando trata das sessões para crianças, quando seleciona para serem exibidos filmes alternativos com temáticas sociais, organiza debates e rodas de conversas. Neste momento pós-olímpico em que fiz o trabalho de campo, pude observar ainda que a desconfiança dos moradores com os meios corporativos de mídia parece ter sido ainda mais acentuado, o que vem sendo frequentemente repassado às crianças.

Já a questão da desobediência territorial não pode ser visualizada com tanta clareza por razões temporais de quando esta pesquisa foi realizada, mas deve ser destacada pela relação que mantém com o espaço da Providência. Em momentos seguintes às remoções e, consequentemente, à tentativa de desmonte da favela, reunir crianças e adultos para articular ações midiáticas também é, de certo modo, promover a desobediência para mais uma tentativa de desmonte da favela.

\section{Considerações finais}

Seria leviano dizer que a Sessão Curumim é o principal fator que motiva o uso de celular com fins midiáticos para crianças da Providência. A proliferação das ferramentas tecnológicas nos últimos anos e a consequente incorporação dos aparelhos também fazem parte do dia a dia de um número incalculável de crianças que vivem nos grandes centros urbanos, de maneira geral. Não é algo exclusivo à realidade do contexto da favela da Providência. 
O projeto é responsável por influenciar um novo uso da ferramenta: uma utilização para que elas não "esperem" por algo que viria da grande mídia e sejam encorajadas a fazerem a própria mídia. Isso não significa também que as crianças vão crescer tendo interesses somente a questões ligadas em lutas sociais. Pelo contrário, é por meio do celular onde assistem a vídeos de youtubers famosos e descobrem desenhos e livros que estão em alta e tratam de diversas temáticas comuns às pessoas de faixa etária similar.

Mas é notável observar que a Sessão Curumim incentiva que o grupo pense em ir além daquilo que está pronto e é dado, midiaticamente falando, além daquilo que está previsto por grandes jornais, o que impacta na construção da identidade delas mesmas e do grupo com quem convivem.

É plausível, portanto, imaginar que o circuito midiático se retroalimenta. Da mesma maneira que as organizadoras do projeto, saturadas da mídia convencional e já na fase adulta da vida, constroem novos hábitos, repassam tais costumes ao público infantil, este mesmo público pode vir a influenciar outras pessoas como os pais, mães, irmãos e núcleos da vizinhança, entre outras pessoas com quem convivem diariamente.

\section{Referências Bibliográficas}

ANTOUN, Henrique; MALINI, Fábio. A Internet e a Rua: Ciberativismo e Mobilização nas Redes Sociais. Porto Alegre, Sulina, 2013, p. 278.

BARROS, Carla. Na Internet Todo Mundo é Feliz: Sociabilidade e Familiaridade no Universo das Camadas Populares. In: EMA - Encontro de Marketing da ANPAD, 2008, Curitiba. Encontro de Marketing da ANPAD - EMA 2008. Rio de Janeiro: ANPAD, 2008.

CASTELLS, Manuel. Redes de indignação e esperança: movimentos sociais na era da internet. Tradução Carlos Alberto Medeiros. Rio de Janeiro: Zahar, 2013.

CRUZ, M. M.. A interação da favela e a cidade formal: processos de sociabilidade mediados pelo ciberespaço. In: Encontro Latino de Economia Política da Informação, Comunicação e Cultura, 2005, Salvador. V ENLEPICC. Salvador: União Latina de Economia Política da Informação, Comunicação e Cultura, 2005.

CUSTÓDIO, Leonardo. Midiativismo de Favela: Reflexões sobre o processo de pesquisa. Finlândia: University Of Tampere, 2016.

FEIGENBAUM, A; FRENZEL, F; MCCURDY, P. Protest camps. Inglaterra, 2013. Disponível em: < http://eprints.uwe.ac.uk/15923/1/ProtestCampsBook_final.pdf> Acesso em: 10 de fevereiro de 2018.

FREITAS, Ricardo F; LINS, Flávio; CARMO, Maria H. Megaevento: uma lógica de transformação social. In: Megaeventos, comunicação e cidade. Rio de Janeiro: CRV, 2016, cap. 1.

JAGUARIBE, Beatriz. Imaginando a "cidade maravilhosa": modernidade, espetáculo e espaços urbanos. Revista FAMECOS, [S.I.], v. 18, n. 2, p. 327-347, 2011. ISSN 1980-3729. Disponível em: <http://revistaseletronicas.pucrs.br/ojs/index.php/ revistafamecos/article/view/9054>. Acesso em: 12 de dezembro de 2016.

KOZINETS, Robert V. Netnografia: Realizando pesquisa etnográfica online. São Paulo: Penso, 2013. 
PARA SE PENSAR E CRIAR OUTROS TIPOS DE NARRATIVAS: TERRITÓRIOS MIDIÁTICOS E MÍDIA TÁTICA PARA CRIANÇAS NO CONTEXTO DA FAVELA DA PROVIDÊNCIA

LEFEBVRE, Henri. Direito à Cidade. São Paulo: Centauro Editora, 2015.

Morar Carioca: O desmantelamento do sonhado Programa de Urbanização para as favelas. In: Rio on Wach, abril de 2014. Disponível em: https://rioonwatch.org.br/?p=12410. Acesso em 20 de maio de 2016.

Prefeitura marca com tinta casas que seriam demolidas na Providência. In: Jornal $O$ Dia, 21 de maio de 2012. Disponível em: http://odia.ig.com.br/portal/rio/prefeituramarca-com-tinta-casas-que-ser\%C3\%A3o-demolidas-1.444020. Acesso em 18 de agosto de 2016.

TOSONI, SIMONE; TARANTINO, Matteo. Media territories and urban conflict: exploring symbolic tactics and audience activities in the conflict over Paolo Sarpi, Milan. International Communication Gazette, 2013. Disponível em: < http://citeseerx.ist. psu.edu/viewdoc/download?doi=10.1.1.1028.856\&rep=rep1\&type=pdf>. Acesso em: 10 de janeiro de 2017. 